\title{
On Translation and Dissemination Mode of Chinese Original COVID-19 Picture Books in the Era of Digital Globalization
}

\author{
Shi Ying \\ Department of Foreign Languages, Zhanjiang Preschool Education College, Zhanjiang, PR China \\ Email address: \\ Shiying06140614@126.com \\ To cite this article: \\ Shi Ying. On Translation and Dissemination Mode of Chinese Original COVID-19 Picture Books in the Era of Digital Globalization. English \\ Language, Literature \& Culture. Vol. 6, No. 1, 2021, pp. 14-17. doi: 10.11648/j.ellc.20210601.13
}

Received: January 16, 2021; Accepted: March 3, 2021; Published: April 1, 2021

\begin{abstract}
In the era of digital globalization, multimedia technology is changing children's reading habits and accelerating the pace of translation and publication of picture books. Since the COVID-19 outbreak in early 2020, the program "Picture Books about COVID-19 for Children Around the World" has been launched. This program appeals for Chinese publishing houses to donate picture books' international copyright and volunteers to offer free translation. Consequently, 11 Chinese original COVID-19 picture books have been translated into foreign languages and published online for free reading within weeks. An innovative mode of translation and dissemination have been adopted in the program. The paper examines three important factors related to its mode, namely what to translate, who translate, the means to promote translation. Then it proposes to seize translation and dissemination opportunities, adopt multi-modal and multi-dimensional transmission routes and through innovative promotion and marketing channels to enhance translation efficiency and expand influence of Chinese picture books in foreign markets.
\end{abstract}

Keywords: COVID-19 Picture Books, Translation and Dissemination Mode, Digital Globalization

\section{Introduction}

For a long time, it has become an indisputable fact that the imported picture books dominate the picture book market in China. Although with joint efforts of publishers, authors, translators and scholars, excellent original Chinese picture books continue to emerge and the translation of picture books continues to pace up, there is still a long way to go before Chinese original picture books can truly "go global". However, it is worth noting that since the outbreak of Covid-19 at the beginning of 2020, the translation and dissemination of Chinese original Covid-19 picture books to foreign countries has been extremely active. For instance, A series of multilingual anti-epidemic books have been published jointly by New World Press and Poplar Kid's Republic. Meanwhile, Phoenix Juvenile and Children's Publishing House has published 6 copies of anti-epidemic book (Big Eyes and Warm Hearts Picture Books), which has been exported to 5 countries. In particular, since the program "Picture Books about COVID-19 for Children Around the World"was launched on February 29, 2020, 11 original Chinese children's books on fighting the epidemic were displayed online in more than a dozen languages on April 2, providing free reading for millions of children around the world [1]. Chinese anti-epidemic picture books have been published in such a fast speed, in such abundant languages and through such wide channels, which is rarely seen. The epidemic is both a challenge and an opportunity. It has further promoted the process of digital globalization. The multimedia technology in the digital age is changing the reading habits of children, speeding up the pace and giving new features of translation and publication of picture books.

Although COVID-19 pandemic has been a hot topic in medical, educational and sociological circles, researches on the translation and publication of COVID-19 books are still insufficient. In western world, some scholars investigate the influences of the COVID-19 pandemic situation on consumer intention to buy books online [2]. In China, Li researches the impact of the COVID-19 pandemic on publishing industry [3]. Wang Lin, Mu Lei describe publishing situation of Chinese anti-epidemic children's books and put forward publishing strategies in the Post-epidemic Era [4]. From the above we can see that most researches are on COVID-19 book publishing and seldom on translation. COVID-19 book 
translation can help spread experience in fighting the epidemic and ease anxiety of children in worst-affected countries. Therefore, researches on VOCID-19 picture books translation are of great significance. This paper takes the program "Picture Books about COVID-19 for Children Around the World"as an example, analyzes the translation and dissemination mode of Chinese original COVID-19 picture books in the context of digital globalization, and strives to provide some enlightenment and reference for the translation and dissemination of Chinese original picture books in the post-epidemic era.

\section{A Review of the Program}

Since the outbreak of Covid-19 at the beginning of 2020, emerging evidence suggests that the COVID-19 pandemic is increasing levels of anxiety and stress. [5] The situation is also true among children. At the end of February, 2020, in order to help ease the anxiety, spread anti-epidemic knowledge and promote understanding and friendship among countries, chairman of IBBY (International Board on Books for Young People) Zhang Mingzhou launched an initiative of providing free anti-epidemic picture books for children around the world. He appealed for the publishing houses to donate picture books' international copyright and volunteers to offer free translation. The initiative received positive responses and IBBY received 60 donated picture books in less than a month. After the experts had selected 11 recommended works and more than 200 volunteers had translated them into dozens of languages (including English, Japanese, French, German, Russian, Spanish, Korean, Italian, etc), these picture books were finally released on Life Tree Books website on April 2 for free reading. The 11 translated picture books are as follows:

1. There is Nothing Much More Than the Virus That Wears a Crown from Sichuan University Press

2. A Journey of 600 Inches from Phoenix Juvenile and Children's Publishing Ltd.

3. Virus go away! from Chinese Children's press and publication Group

4. Fight Bacteria from Shanghai People's Fine Arts Publishing House

5. A special Spring Festival from Qingdao Publishing House

6. Agan Will Win from Publishing House of Electronics Industry

7. Virus, Virus, You Can't Scare Me! from Yunnan Aurora Publishing House

8. The Illustrated COVID-19 Prevention Manual from Instant Research Institute

9. A Brief History of Virus for Children from Changjiang Children's Press

10. Waiting for Dad to Come Home from Changjiang Children's Press

11. Ten Tips to Fight Monsters from Beijing Science and Technology Publishing CO. Ltd

This program has exerted great influences and has been reported by mainstream media at home and abroad. Currently, many countries, including South Korea, Thailand, Japan, Mongolia and Cambodia, are introducing the website to their children [6]. The website has received nearly 20,000 views from 53 countries within a month since its launch. Some famous foreign journals have dedicated a few pages on these translated books [7]. Over Drive, the world's largest book provider for libraries, recommends the above epidemic picture books to 45 thousand libraries in 78 countries [1]. It is safe to say the translation of these epidemic picture books was a great success and it will exert a far-reaching influence on the creation, publication and translation of Chinese original picture books.

\section{Translation and Dissemination Mode}

The translation and dissemination of literary works are dependent on several factors. What to translate, who translate and means to promote translation are decisive factors. The following part analyzes translation and dissemination mode of the anti-epidemic picture books in three aspects.

\subsection{What to Translate}

Choosing appropriate works ensures translation quality and translation effect. The plot, genre and the writer of the work should be considered before it's translated [8]. In the program, the 11 translated books are chosen because of its high quality. "These 11 books have both scientific knowledge and aesthetic quality. They are universal in culture and appropriate for children." says an expert [1]. For example, non-fiction books The Illustrated COVID-19 Prevention Manual and A Brief History of Virus for Children make scientific knowledge interesting. Fiction books A Journey of 600 Inches and Agan Will Win teach children knowledge through stories. Besides, these picture books are well designed and finely illustrated. In a word, they are appropriate for young readers.

Another factor is translatability of the work. Not all excellent original works should be translated. As Xie Tianzhen proposes, "When translating Chinese literary works and classics to foreign countries, translators should choose those works that are translatable, that is, those works that are easy to be accepted in target language culture.'[9] In this program, when choosing works to translate, experts exclude nursery rhymes, posters and wall charts because they are not easy for translation.

\subsection{Who Translate}

Translator's competence and professional accomplishment play an important role in the success of translated works. Anti-epidemic picture books are translated by a team of more than 200 people, most of whom are teachers and students from Shanghai International Studies University. This group also includes famous translators such as Ma Ailong and $\mathrm{Wu}$ Gang. The great number of translators ensures translation efficiency and the guidance from famous translators ensures translation quality. Translators accomplished as many as 88 
translated versions in dozens of languages within a month. Professor Wu Gang, the team leader, exclaimed, "It is really a wonder that we have completed such a big program without payment!"

The translation process of COVID-19 books is composed of preliminary translation, terminology management, proofreading, draft checking, and format checking [6]. Clear division of labor and explicit processes ensure translation quality. When comparing the English and Chinese versions of picture books, we will find the translated version accurately reproduces the main content of the original text and retains the cultural characteristics and style of the original text. For example, the original Chinese text “这种病毒很厉害吗? ” is translated into “Is the virus scary?” “我问妈妈”is translated into "Worried, I asked mom." Translators adopt a flexible method to ensure the translated language vivid.

\subsection{Means to Promote Translation}

Generally speaking, there are two ways to translate Chinese literary works: One is "active translation" led by Chinese official agencies and the other is "overseas publishing" led by foreign mainstream publishing houses [10]. The program introduced original Chinese anti-epidemic picture books through an innovative way of donating international copyright. It eliminates the needs to find international book agencies, seek overseas publishing houses, draw up copyright contracts and other complicated processes, which greatly improves translation efficiency.

Network publishing is another innovative means to promote translation. In the era of digital globalization, "networking", "digitalization" and "virtualization" have become main features [11]. During quarantine period, publishing houses have adopted digital publishing, such as the publishing of e-books and audio books. In this situation, the program took the opportunity to release dozens of translated versions online. This multilingual online publishing has an instant and large-scale impact, which is rare for children's literature.

\section{Enlightenment}

Chinese original anti-epidemic picture books are successfully translated because the works are well chosen, the translators are qualified and the organizers adopt innovative means to promote translation. It has spread China's anti-epidemic experience, expanded influence of Chinese picture books, and also provided enlightenment for the future translation and dissemination of Chinese original picture books.

Firstly, we should seize every opportunity to promote translation and dissemination of Chinese picture books. In recent years, domestic children's publishing houses have actively worked with foreign publishers, but the total amount of translation and overseas publication is still limited. One reason is the wrong timing of copyright export. Undeniably, Chinese literature and culture going abroad is actually a kind of 'countertrend', which means the translation and introduction is one from weak culture to strong culture [9]. This kind of "countertrend" translation is not easy. It seems particularly important to choose the appropriate timing of translation. The publishers should consider the hot issue of foreign book market and cater to local culture and life.

Secondly, in the era of digital globalization, a multi-modal and multi-dimensional way will promote translation efficiency. "The new media technology in the digital age makes text, image and sound effectively integrated." [11] Literature dissemination should also conform to the times and adopts a multi-modal and multi-dimensional way. This project adopts network publication model, which not only improves the efficiency of translation, but also realizes online reading for young readers during home quarantine. It is suggested that the publishers offer audio books, and related APP, or adapt these COVID-19 picture books into online videos, children's musicals, and children's movies etc. The multi-modal and multi-dimensional transmission path which combines text, image, audio and video is bound to expand the oversea influence of Chinese anti-epidemic picture books.

Thirdly, innovative promotion and marketing channels help to expand influence in foreign book markets. The translation of a literary work is only the first step towards foreign markets. The overseas promotion of literary works needs the cooperation of author, translator, copyright exporter and copyright importer. It also involve a series of routine initiatives, such as book launches, celebrity reviews and mainstream media report. In addition, innovative promotion and marketing channels are essential. The reason why this project has received a warm response in overseas markets is that it is widely reported by mainstream media and highly recommended by prominent figures in children's literature and publishing circles. It is also because of the spirit of dedication. For this project, 50 publishers, authors and illustrators donated the copyright, 300 volunteers translated for free and donated the translation to overseas countries. Just as some scholars stated, increasingly, volunteer translators have been using social media platforms to self-organize and carry out urgent translation tasks that effectively complement official disaster relief efforts.[12] In this project, volunteer translators acted quickly to spread China's experience of fighting the epidemic to the world and helped Chinese COVID-19 picture books successfully and smoothly go into the overseas markets.

\section{Conclusion}

In the era of digital globalization and during the quarantine period, original Chinese COVID-19 picture books have successfully transcended the linguistic and cultural barriers, and become well-received by the young readers in foreign markets. Its success attributes to effective translation and dissemination mode, namely experts' careful selection of works, efforts of groups of volunteer translators, and innovative means to promote translation. The enlightenment 
it offers is to seize every opportunity to promote translation and dissemination of Chinese picture books, adopt multi-modal and multi-dimensional transmission routes and through innovative promotion and marketing channels to enhance translation efficiency and expand influence of Chinese picture books in foreign markets.

\section{Acknowledgements}

This research was supported by the 2019 Guangdong Youth Innovative Talents Project "A Study on the English Translation of Chinese Children's Literature in the New Century from the Perspective of Systematic Functional Linguistics"(2019GWQNCX156); 2019 Zhanjiang Preschool Education College Project "Translation Studies on Picture Books from the Perspective of Multimodality" (ZJYZYB201904).

\section{References}

[1] Lifetreebooks. (2020, 6 May). 300 volunteers translated Chinese children's books into more than 10 languages to help children from the world fight the epidemic. Retrieved 16 January 2021 from https://www.lifetreebooks.org.cn/pc/news/detail.html?id=48.

[2] Hoang Viet Nguyen (et al, 2020) Online Book Shopping in Vietnam: The Impact of the COVID-19 Pandemic Situation. Publishing Research Quarterly, 36, 437-445.

[3] Li Jingli. (2020) The Impact of the COVID-19 Pandemic on Publishing Industry and Countermeasures. Publishing and Printing, 2, 1-7.
[4] Wang Lin, Mu Lei (2020) On the Publishing Strategies of Children's Books in China in the Post-epidemic Era. Technology and Publishing, 7, 92-96.

[5] Prerna Banati (et al, 2020) Intersecting Vulnerabilities: The Impacts of COVID-19 on the Psycho-emotional Lives of Young People in Low-and Middle-income countries. The European Journal of Development Research, 32, 1613-1638.

[6] Liu Beiei, Han Yang. (2020, 20 April). Life tree books website offers free translations of 11 Chinese anti-epidemic children's books into more than 10 languages. Retrieved 16 January 2021 from http://www.qkblh.com/plus/view.php?aid=32552.

[7] Björn Sundmark (2020) Children's COVID-19 Literature. Bookbird: A Journal of International Children's Literature, 58 (3), 84-85.

[8] Zhao Jirong. (2020). Chinese children's literature "going out": an analysis of the current situation of foreign translation and introduction. Journal of Guangdong University of Foreign Studies (2), 128-138.

[9] Xie Tianzhen. (2014). Chinese Literature Going Out: Problem and Essence. Chinese Comparative Literature, 94 (1), 1-10.

[10] Dong Haiya. (2017). On Translation and Dissemination of Chinese Children's Literature in English-speaking Countries. Shandong Foreign Language Teaching, 38 (5), 88-95.

[11] Wu You, Chen Taoqiu (2020). Translation and International Dissemination of Liu Cixin's Science Fiction in the Age of Digital Globalization. Journal of SJTU (Philosophy and Social Sciences), 28 (6), 33-45.

[12] Jie Zhang and Yuqin Wu (2020). Providing Multilingual Logistics Communication in COVID-19 Disaster Relief. Multilingua 39 (5): 517-528. 